\title{
More riches for Japan
}

\section{Tokyo}

SPACE science, astronomy and research on the global environment receive strong backing from the Japanese government in an expansionary budget for science and technology released last week.

The Ministry of Education, Science and Culture (MESC), the Ministry of International Trade and Industry (MITI), the Environment Agency and the Ministry of Health and Welfare all receive significant increases for science-related items, as did the Science and Technology Agency (see Nature 343, 195; 18 January 1990). Several new projects are provided for.

The budget was approved by the Ministry of Finance and the cabinet at the end of last month and will run from April.

Even though some delay is now possible because of resistance from the newly strengthened opposition parties in the Diet, the outlays for science and technology are unlikely to be much affected.

Japan's astronomers seem set to achieve their dream of building a huge 7.5metre infrared telescope on Hawaii after years of lobbying. The Ministry of Finance has approved a tiny budget of $¥ 13$ million $(\$ 90,000)$ in preparatory funds for the telescope, construction of which is eventually expected to cost about $¥ 45,000$ million ( $\$ 320$ million). But Makoto Kinoshita of MESC's science and international affairs bureau stresses that there are many hurdles still to be overcome before the project is realized.

More clear-cut is approval of $¥ 845$ million (\$6 million) to build a heliograph at the Nobeyama Radio Observatory. The heliograph will consist of a T-shaped array of $7680-\mathrm{cm}$ parabolic antennas, and is expected to be completed in two years at a cost of $¥ 1,900$ million.

MESC's budget for space science decreases slightly in 1990 but it contains an important new allocation of $¥ 1,850$ million (\$13 million) to develop a new solidfuel rocket for the Institute of Space and Astronautical Science (ISAS). The rocket will have three times the power of the institute's present biggest rocket, the MU3SII, which this week is expected to send Japan's first probe to the Moon. The new rocket will take four years to develop at a cost of about $¥ 20,000$ million.

The most striking feature of MITI's budget is a huge new outlay of $¥ 6,274$ million ( $\$ 45$ million) to develop new technology and products to protect the global environment. MITI plans to use the funds at a new institute that will be set up as a foundation with donations from industry later this year.

The Environment Agency also gets a huge boost in its budget for the global environment. Most of the extra funds go to new research grants ( $¥ 1,200$ million) for universities and research institutes in Japan and overseas, and to the establishment of a new centre for global environment research at the agency's National Institute for Environmental Studies in Tsukuba ( $¥ 285$ million).

MESC also gets new funds to reorganize the Research Institute of Atmospherics at Nagoya University into the provisionally named Solar-Earth Environment Research Institute where fluxes of energy and materials from the Earth and Sun and their effect on the global environment will be studied. The National Institute of Polar Research, which until now has devoted its attention to the Antarctic, will establish an Arctic research centre. And the Sand Dune Research Institute of Tottori University will be reorganized to tackle research on the deserts of the world as well as its current research of local sand dunes.

MITI continues to pour money into the development of superconductors and into its fifth generation computer project which will end in 1992. The budget for a small unmanned space platform, the Space Flyer Unit, being jointly developed by MITI, ISAS and STA for launch in fiscal year 1994, also rises as it nears completion.

Funding for a ten-year project to study cancer initiated in 1984 with the backing of former prime minister Yasuhiro Naka-

\section{One step forward, one step back}

\section{Washington}

THE space shuttle Columbia landed at Edwards Air Force Base in southern California early last Saturday morning, a day late because of bad weather but with the Long Duration Exposure Facility (LDEF) safely stowed in its cargo bay. LDEF will be taken back to the Kennedy Space Center before it is removed from Columbia and its numerous onboard experiments unpacked and analysed (see Nature 342, 847; 1989).

The day before Columbia landed, the National Aeronautics and Space Administration announced that the launch of the Hubble Space Telescope has been set back once more, this time from 26 March to 19 April. Engineers decided to remove one of the solid rocket booster and replace one segment of it because their records did not show whether or not one of the O-ring joints had been fully tested for leaks.

David Lindley

sone (see Nature 310, 264; 1984) has been rising dramatically in recent years. The project is jointly funded by MESC, STA and the Ministry of Health and Welfare. But possibly the most significant item in the Ministry of Health and Welfare budget is a small outlay of about $¥ 300$ million ( $\$ 2$ million) to begin a project to sequence human oncogenes.

David Swinbanks

JAPANESE SCIENCE BUDGET

Ministry of Education, Science and Culture

Grants-in-aid of research

Government/industry research

Donations from industry

Domestic research fellowships

Nuclear fusion

Accelerator physics (TRISTAN)

Space science

Astronomy

Global environment

Earth science

Antarctic research

International exchange

Environment Agency

Global environment

Ministry of International Trade and Industry (MITI)

Total R\&D budget

Japan Key Technology Centre

Basic technologies for future industries

Large-scale industrial projects

Sunshine project

Moonlight project

Unmanned space platform

Superconductivity

Fifth-generation computer

Global environment

Ministry of Health and Welfare

Total R\&D budget

AIDS

Cancer (10-year project)

1987

$\begin{array}{cc}1988 & 1989 \\ \text { (thousand million yen) }\end{array}$

1990

(\% change
from 1989)

45.1
7.9
NA
1.1
7.7
12.9
11.8
NA
NA
2.1
2.9
5.5

48.9
8.9
NA
1.5
7.6
16.5
19.8
NA
NA
2.1
2.8
6.6

52.6
10.3
33.2
1.9
8.5
15.9
20.8
NA
3.0
2.2
2.9
5.8

$55.8+6.1 \%)$

$11.5(+11.9 \%)$

$39.2 \quad(+18.0 \%)$

$2.2(+14.1 \%)$

$8.9(+\quad 4.1 \%)$

$\begin{array}{rr}8.9 & (+2.1 \%)\end{array}$

18.0 (- 13.3\%)

0.9

3.9

$(+30.6 \%)$
$+\quad 4.6 \%)$

$+74.3 \%)$

$\begin{array}{ll}5.1 & (+74.3 \%) \\ 6.2 & (+6.1 \%)\end{array}$

NA, equivalent budget not available.

*Includes budgets for Ministry of Education, Science and Culture ( $¥ 2.1$ thousand million) and Science and Technology ( $¥ 7.9$ thousand million)

1)

221.4

25.0

6.0

15.1

44.1

11.4

0.4

NA

5.6

0.3

0.9

2.1

$(+142.0 \%)$

221.2

26.0

6.4

13.6

37.8

9.7

0.5

2.7

5.7

233.6

26.0

6.8

13.9

27.1
10.7

4.5

3.8

6.5

1.0

249.8

26.0

7.5
14.1

14.1
27.5

11.6

5.3

5.0
7.0

7.0
6.3

(+ $6.9 \%$ )

(+ $0.0 \%)$

(+ 13.0\%)

(+ $1.2 \%$ )

(+ $7.8 \%$ )

(+ 17.5\%)

(+ 29.3\%)

(+ $7.6 \%$ )

$(+530.0 \%)$ 